\title{
An investigation of involute and lead deflection in hot precision forging of gears
}

\author{
Bin $\mathrm{Zuo}^{1} \cdot$ Baoyu Wang ${ }^{1} \cdot \mathrm{Zhi} \mathrm{Li}^{1} \cdot \operatorname{Nan} \mathrm{Li}^{2} \cdot$ Jianguo Lin ${ }^{1,2}$
}

Received: 20 March 2016/Accepted: 31 May 2016/Published online: 11 June 2016

(C) The Author(s) 2016. This article is published with open access at Springerlink.com

\begin{abstract}
A theoretical model is presented in the paper for predicting involute profile deflection in hot precision forging of gears. This model is a function of a number of material and processing parameters, including the thermal expansion of the die, thermal contraction of workpiece, elastic expansion of the die during forging, and workpiece recovery after ejection. To improve the accuracy of the hot forged gear tooth, an equation set to define modified involute that is used to design the die tooth has been proposed based on the model. The distribution of deflection along the involute was also predicted using the commercial FE code, PRO-E. The deflection characteristic of the toothed die through the tooth width was analyzed by combining the theoretical method and FEM to investigate the nonuniform deflection. The dimension of the forged gears was measured using a gear measurement machine WGT3000. A close agreement between predicted and measured tooth involute profiles was obtained, which validated the involute deflection prediction model. The measured lead error also verified the model for deflection non-uniformity through the tooth width. The results can provide a guide for die tooth designs to improve the dimensional accuracy of hot forged gear teeth.
\end{abstract}

Keywords Hot precision forging · Gear forging · Tooth deflection · Involute modification · Thermal expansion

Jianguo Lin

Jianguo.Lin@Imperial.ac.uk

1 School of Mechanical Engineering, University of Science and Technology Beijing, Beijing 100083, People's Republic of China

2 Department of Mechanical Engineering, Imperial College, London, UK

\section{Introduction}

The market demand for gears has been increased significantly in recent years [1]. High accuracy, productivity, and the capability in gear manufacturing have been receiving significant attentions [2]. Conventional machining processes for manufacturing gears can meet the requirement of accuracy, but it has low productivity with material wastes, and the strength and fatigue life of machined gears are lower than those of the gears produced through forging processes [2]. Forged gears have been presented as having the advantages of high-strength teeth [3], high productivity, and low-power dissipation [4]. Additionally, great utilization of raw material is one of the advantages in using gear forging $[5,6]$.

Due to the high forming load required in precision gear forging [7], researchers have focused on different structures and shapes in designs of tools in order to reduce forming load. The benefits of low forging force include low distortion, improved dimensional accuracy, and long tool life [8]. An alternative die design was proposed by Cai et al. [8] to enhance filling of the bottom corners of teeth. They also proposed a chamfered punch to reduce forming load. The idea of relief axis and relief hole based on a divided flow principle was used in gear forging by Kondo et al. [9] to reduce forming load and contribute to complete die filling. This resulted from inward material flow through a relief axis and a relief hole [9]. A new cold precision forging process proposed by Wang et al. [10] suggested that the spur gear forging process should be divided into two steps, which improved the filling of the teeth and reduced the forging load by $30 \%$ [10]. Alves et al. [11] developed a flexible cold forming tool system, which was used to forging spur gears.

Although forged gears have many advantages compared with machined gears, the problem of controlling the accuracy of hot forged gear teeth is difficult to solve [12]. In recent 
years, studies on forging gears have been practiced in industrial production. However, for large spur and helical gears in particular, only gears with low accuracy can be manufactured through forging, and in general, only gear blanks are forged for subsequent machining. Thus, forging gears with proper accuracy control has become the research emphasis. Liu et al. [13] improved the accuracy of cold forged gears to level 7 in Chinese industrial standard (close to ISO 5) by correcting tooth profile through simulation results using finite element method (FEM). A new tool-manufacturing procedure that considered shrink fitting was suggested by Kanga et al. [14] to increase tool-manufacturing precision. Choi et al. [14] forged spur gears made of alloy steel (SCM415) with inside relief in two steps of forging process. Their proposed method not only decreases forging load but also improves forging accuracy to fourth and fifth classes in the Korean industrial standard, which is close to the accuracy of a machined spur gear [15]. Another process, known as cold ironing, which is used to obtain high surface finish and accuracy, was investigated by Stone et al. [16] and Chang et al. [17] as a postprocess for net-shape manufacturing of gears, which has improved the accuracy of hot forged gears significantly.

The deformation resistance of material in hot forging is much lower than that in cold forging because of the lower flow stress and higher formability of materials at elevated working temperatures. Thus, forging load and filling difficulty in tooth corner are lower in hot forging than those in cold forging, which enables larger gears to be forged. However, complex tooth deflections in hot forging processes affect the accuracy of formed gears. Little research on the accuracy of hot forged gears has been conducted, apart from the studies conducted by Sadeghi et al. [18] on the effects of forging parameters, such as forging load, forging temperature, die preheat temperature, and spark gap on the final dimensions of hot precision-forged axisymmetric components.

Improving the accuracy of hot forged gears benefits the subsequent process of fine machining, such as reducing machining allowance and improving production efficiency [19, 20]. To improve forging accuracy, the following four factors that affect tooth profile accuracy are studied in the research: thermal expansion of die, thermal contraction of workpiece, elastic expansion of die, and elastic recovery of workpiece after ejection. A model for the calculation of the involute deflection caused by the aforementioned factors was presented. To design the die tooth profile, a modified involute was proposed based on the deflection model. The involute deflection of die and workpiece was predicted using FEM, and the tooth profile of a forged gear was measured using the gear measurement machine WGT3000. Deflection non-uniformity of the toothed die through the tooth width was analyzed by combining a theoretical method with FEM prediction. The measured lead profile also verified the model, which was used to predict the nonuniform deflection through the tooth width.

\section{Tool design and fabrication}

A spur gear in an automotive gearbox was used to study the dimensional accuracy of hot forged gear teeth. The parameters of the gear were as follows: number of teeth, 26; modulus, 2.7285; and normal pressure angle of pitch circle, $20^{\circ}$. The tool set with toothed die is shown in Fig. 1. The toothed die was mounted on the machine bed sitting on several light springs; such that, it could move downward together with the punch (number 2-top die and number 3-mandrel; Fig. 1) during forging. The benefit of this was to enhance filling of the bottom corners of the teeth by changing the friction condition. The tooth width of the die is defined as $b$ and the die width as $B$. A cylindrical load cell with a group of full-bridge strain gauges on the outer surface is used to measure the forming load.

The hot forging tool material of $\mathrm{H} 13$ was used for punch, mandrel, toothed die, and counter punch and was hardened over HRC52. The other parts were made of $40 \mathrm{Cr}$ steel and were hardened to HRC40-45. The die teeth were manufactured by electrical discharge machining (EDM) and the tool set is shown in Fig. 2.
Fig. 1 Tool set with toothed die at the open (left) and closed (right) tool positions. 1 load cell, 2 top die, 3 mandrel, 4 toothed die, 5 bottom die/ejector, 6 springs, 7 die container, and 8 die insert

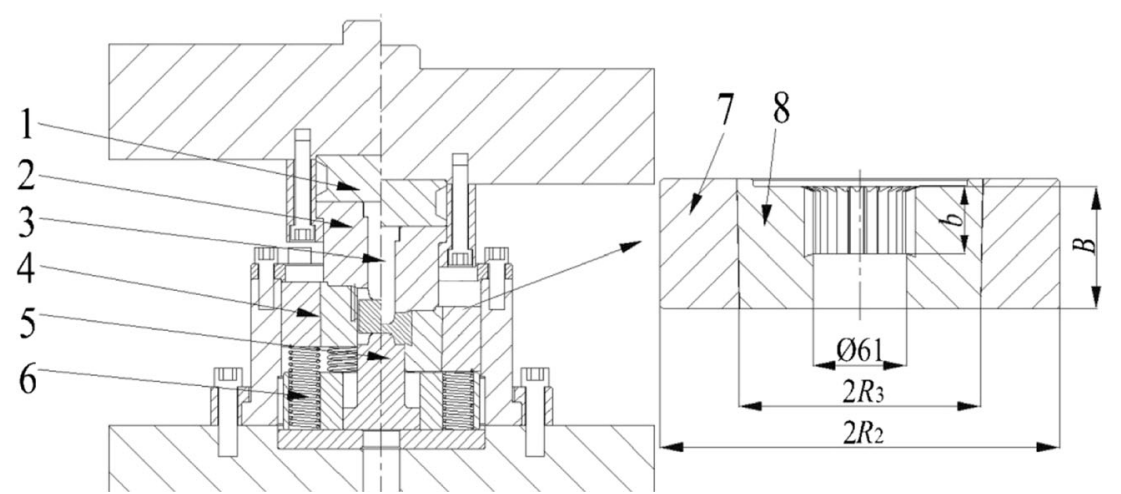




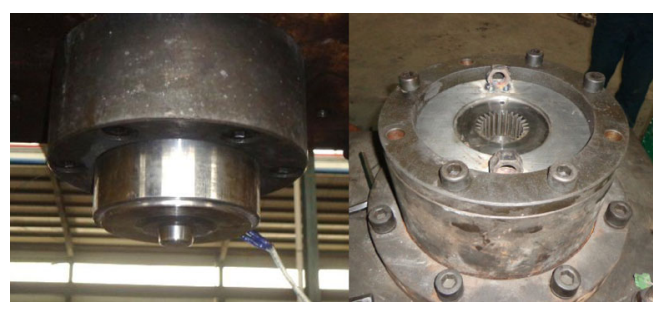

(a) Punch

(b) bottom die

Fig. 2 Photos of the tool set, a upper and $\mathbf{b}$ bottom die set

\section{Involute deflection in hot precision forging of gears}

Figure 3 represents the effect of process parameters on the dimensions of the die cavity (left part) and workpiece (right part) in a gear-forging process. The initial radius of die cavity, $R$, would be increased by a certain amount, $t_{d}$, as a result of the die expansion as the die is heated to the preheating temperature before forging. During forging, the billet deformed and filled the die cavity. Consequently, the die radius of cavity would expand elastically by a certain amount, $e_{d}$, due to the high forging load. At this moment, the inner radius of the die, $R^{\prime}$, is the same as the outer radius of the workpiece, $r^{\prime}$. Then, the elastic recovery of workpiece occurred as the forged gear is ejected from the die, and the radius of the workpiece would be increased by a certain amount, $e_{w}$, due to elastic recovery. Thermal contraction caused by cooling the workpiece to room temperature would reduce the workpiece radius by a certain amount, $t_{w}$. The final outer radius of the forged part is $r$. Thus, the difference between $R$ and $r$ is the dimensional difference in radius between the die and the forged part, $U$, as shown in Eq. (1).

$U=R-r$

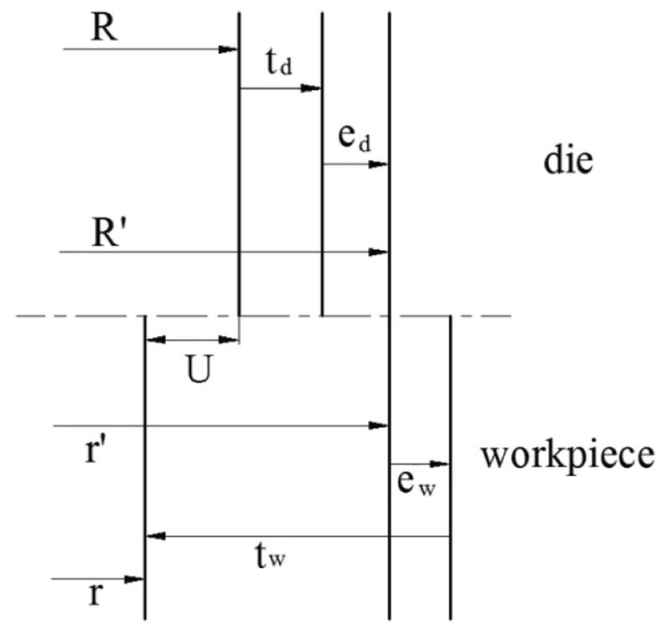

Fig. 3 Tooth deflections of die and workpiece in hot precision forging
According to the relation among the parameters discussed above, the dimensional difference in terms of radius, $U$, is represented by Eq. (2).

$U=e_{d}+t_{d}+e_{w}-t_{w}$

A free point, $P_{i}$, on the involute profile, where the distance to the gear center is $r_{i}$, tooth thickness is $s_{i}$, and tooth height is $h_{i}$, was taken to study tooth deflection (also see Fig. 4). In the last stage of forging process, the die container was fully filled. The workpiece and toothed die were multiaxially compressed. Thus, the deflection caused by the elastic die expansion and workpiece recovery was divided into radial direction and circumferential direction, while the thermal deflections that occurred only in radial direction are considered, since this is the major dimension/tolerance, which needs to be considered in die design for precision gear forging.

\section{Deflection characteristic of involute profile}

\subsection{Modeling of each deflection}

\subsubsection{Thermal deformation}

In hot forging, thermal deformation of die and workpiece being considerable is an important factor that influences the tooth profile. The degree of influence depends on the temperature variation and the coefficient of thermal expansion of the material. The dimensional variation can be calculated with the well-known thermal expansion formula, as shown in Eq. (3).

$t=\beta \cdot \Delta T \cdot L$

where $\beta, L$, and $\Delta T$ are the coefficient of thermal expansion, the dimension of object, and the variation of temperature.

\section{Thermal die expansion caused by preheating}

The die was preheated to a specified temperature before forging to prevent die cracking, to reduce billet cooling, and to help lubricant coating on the die surface. The die set was reheated to the temperature, $T_{p}$, using a band heater. It is assumed that the temperature distributes uniformly over the die in the modeling of deflection caused by the thermal expansion in preheating. Furthermore, the thermal expansion occurs without constraints. To calculate the thermal deflection on tooth profile, $L$ in Eq. (3) is equal to the parameter $r_{i}$ of the free point $P_{i}$. Thus, die expansion on a tooth in radial direction can be modeled using

$t_{d}=\beta_{d}\left(T_{p}-T_{0}\right) r_{i}$

where $T_{0}$ and $\beta_{d}$ are the room temperature and the coefficient of thermal expansion of die material, respectively. 
Fig. 4 Elastic expansions of the toothed die, a deflection analysis that is divided into two zones and the partial enlargement around $P_{i}$ and $\mathbf{b}$ duplex cylinder subjected to internal pressure

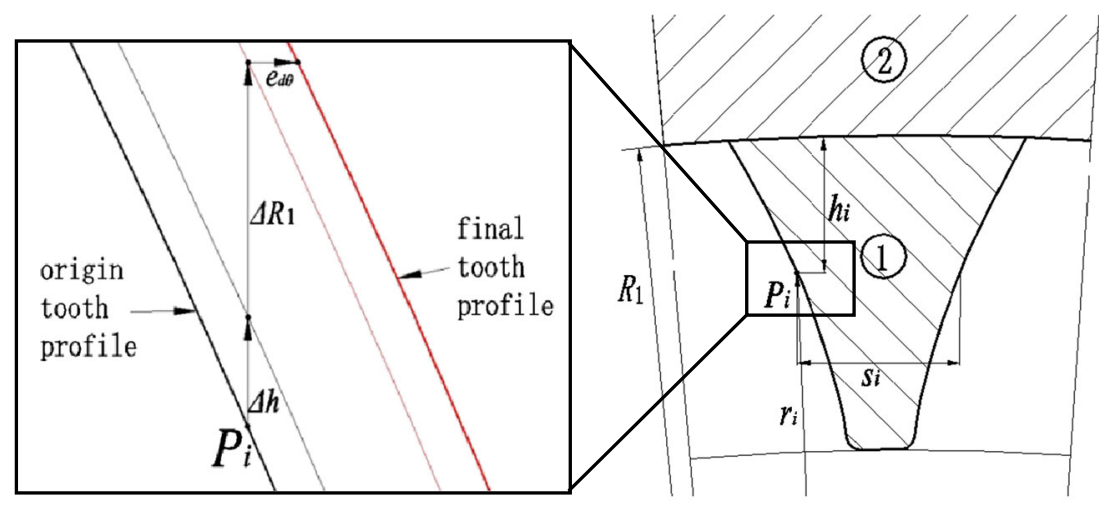

(a) Deflection

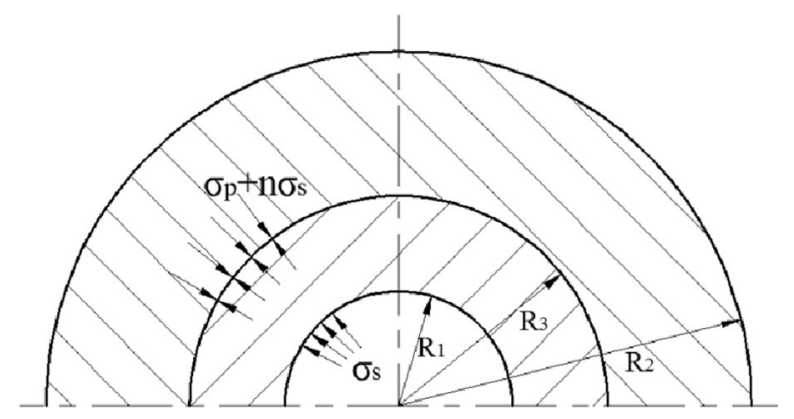

(b) Internal pressure
2. Thermal die expansion caused by heat transfer from workpiece

Further temperature rise of the toothed die occurred due to the heat transfer from the workpiece. Heat flow was outward with a radial temperature gradient. However, this phenomenon could be considered to occur after the completion of forging process and before the ejection, given that the duration of forging process was very short. The workpiece remaining in the container would recover elastically with the thermal expansion of die caused by heat transfer, which led to stress reduction in the workpiece. The effect of temperature rise and thermal expansion of die would be removed after forging by cooling the die in production procedure. This die deformation is also related to the elastic recovery of workpiece, which is described in Sect. 4.1.3.

\section{Thermal workpiece contraction}

The forging temperature of workpiece, $T_{f}$, would decrease to room temperature, $T_{0}$, after completion of forging process. Thus, the amount of this contraction on tooth in radial direction is determined with Eq. (5).

$t_{w}=\beta_{w}\left(T_{f}-T_{0}\right) r_{i}$

where $\beta_{w}$ is the coefficient of thermal expansion of billet material. The heat loss caused by thermal transfer to the die and the heat generated by the deformation during forging is small and can partially cancel out; thus, they are neglected.

\subsubsection{Elastic die expansion during forging}

During forging, wherein duplex toothed dies were used, the billet was deformed under the axial pressure through the punch and flows to the corners of the die container with a normal pressure exerted on the container wall. When the punch was removed, the axial pressure became zero, and the container compressed the workpiece until the normal stress that acts on the workpiece was reduced to the yield stress of billet material, $\sigma_{s}$, which is equal to the flow stress of the billet material at elevated temperature. Thus, only the dimensional change, caused by the residual elastic expansion of the die after the punch was removed, should be considered and the toothed die is expanded radially by normal stress $\sigma_{s}$ at this time [12]. Furthermore, the die deflection is assumed uniform along the die axis.

\section{Radial deflection}

Calculating radial deflection on the tooth is separated into that occurring in the following two zones (Fig. 4a): tooth (zone (1)) and cylinder (zone (2)) with bore radius $R_{1}$ (addendum circle radius). First, the deflection, $\Delta h$, of zone (1) is calculated. Second, the amount of elastic expansion, $\Delta R_{1}$, of zone (2) is calculated, which is equal to the rigid body displacement of zone (2), supposing zone (2) is rigid. Finally, $\Delta h$ 
and $\Delta R_{1}$ are added together. The deflections in different directions of two zones, which reflected on the involute profile, are shown in the partial view in Fig. $4 \mathrm{a}$.

Zone (1) can be considered as a cube, which is compressed in both radial and circumferential directions, by ignoring the effect of frictional shear stress to the deflection, given that the effect is much less than that of normal pressure. Thus, the radial dimension variation, $\Delta h$, can be calculated by the generalized Hooke's law.

$\Delta h=\frac{1}{E}(1-\rho) \sigma_{s} \cdot h_{i}$

where $h_{i}$ is the distance between the point $P_{i}$ and addendum circle, $E$ is the Young's modulus, and $\rho$ is the Poisson's ratio of the die material

Zone (2) can be considered a thick-walled cylinder, which is under a uniform internal pressure of $\sigma_{s}$ and interfacial pressure of $\sigma_{p}+n \sigma_{s}$, as shown in Eqs. (7) and (8) and Fig. 4b. The longitudinal pressure is assumed to be zero when the forging operation is completed. The radius and diameters of the die bore are equal to those of addendum circle, $R_{1}$ and $D_{1}$, of the gear. The radial displacement, $\Delta R_{1}$, is shown in Eq. (9) [12].

$\sigma_{p}=\frac{E \delta}{2 R_{3}^{3}} \frac{\left(R_{3}^{2}-R_{1}^{2}\right)\left(R_{2}^{2}-R_{3}^{2}\right)}{\left(R_{3}^{2}-R_{1}^{2}\right)}$

$n=\frac{R_{1}^{2}}{R_{2}^{2}-R_{1}^{2}}\left(1-\frac{R_{3}^{2}}{R_{2}^{2}}\right)$

$\Delta R_{1}=\frac{R_{1}^{3}(1-\rho)+R_{1} R_{3}^{2}\left(1+\rho^{-2 n)}\right.}{E\left(R_{3}^{2}-R_{1}^{2}\right)} \cdot \sigma_{p}$

where $E$ and $\rho$ are the Young's modulus and Poisson's ratio of the die martial, $\sigma_{p}$ is the fitting stress, $\delta$ is the radial interference between the container and toothed die, $n$ is the attenuation coefficient of $\sigma_{s}$ at mating surface, and $R_{2}$ and $R_{3}$ are the outer radius of die container and die insert, respectively, as defined in Fig. 1.

The amount of the total radial deflection $e_{\mathrm{dr}}$ is shown in Eq. (10).

$e_{\mathrm{dr}}=\frac{1}{E}(1-\rho) \sigma_{s} h_{i}+\frac{R_{1}^{3}(1-\rho)+R_{1} R_{3}^{2}(1+\rho-2 n)}{E\left(R_{3}^{2}-R_{1}^{2}\right)} \sigma_{s}$

\section{Circumferential deflection}

The circumferential pressure on the cylinder die wall (zone (2)) does not affect the container dimension. Thus, only the tooth zone should be considered for circumferential deflection. The dimensional variation of circumferential deflection, $e_{d \theta}$, can be calculated with the generalized Hooke's law, as shown in Eq. (11).

$e_{d \theta}=\frac{1}{E}(1-\rho) \sigma_{s} \frac{s_{i}}{2}$

\subsubsection{Elastic workpiece recovery during ejection}

After completion of forging process and before ejection, the workpiece remains in the die and is compressed under the pressure exerted by the die bore as a result of the elastic deformation of the die. On ejection, the pressure becomes zero, and the workpiece expands elastically. The amount of this expansion can be determined by the stress state of workpiece and the generalized Hooke's law (Eq. (12)).

$\left\{\begin{array}{l}\varepsilon_{r}=\frac{1}{E^{\prime}}\left\{\sigma_{r}-\rho^{\prime}\left(\sigma_{\theta}+\sigma_{z}\right)\right\} \\ \varepsilon_{\theta}=\frac{1}{E^{\prime}}\left\{\sigma_{\theta}-\rho^{\prime}\left(\sigma_{r}+\sigma_{z}\right)\right\} \\ \varepsilon_{z}=\frac{1}{E^{\prime}}\left\{\sigma_{z}-\rho^{\prime}\left(\sigma_{\theta}+\sigma_{r}\right)\right\}\end{array}\right.$

where $\sigma_{r}, \sigma_{\theta}$, and $\sigma_{z}$ are the stresses in three directions and $E^{\prime}$ and $\rho^{\prime}$ are the Young's modulus and Poisson's ratio of the billet material, respectively. Before ejection, the top die is lifted up, and the toothed die compresses the workpiece to the yield stress. Thus, $\sigma_{z}=0$ and $\sigma_{r}=\sigma_{\theta}=\sigma_{s}$. The strain state of the workpiece can be described as Eq. (13).

$\varepsilon_{r}=\varepsilon_{\theta}=\frac{\sigma_{s}}{E^{\prime}}\left(1-\rho^{\prime}\right)$

The radial variation in dimension $e_{\mathrm{wr}}$ can be calculated with Eq. (14).

$e_{\mathrm{wr}}=\frac{1-\rho^{\prime}}{E^{\prime}} \sigma_{s} r_{i}$

where $\sigma_{s}$ is the flow stress. $E^{\prime}, \rho^{\prime}$, and $r_{i}$ are the Young's modulus, Poisson's ratio of the billet material, and the distance to the gear center.

Similarly, circumferential deflection of the elastic recovery $e_{w \theta}$ can be determined by the following equation:

$e_{w \theta}=\frac{1-\rho^{\prime}}{E^{\prime}} \sigma_{s} \frac{S_{i}}{2}$

where $s_{i}$ is the gear thickness.

\subsection{Modification of the shape of the involute die tooth}

According to the model in the previous section, each deflection along the involute profile can be defined as a function 
with respect to the variable $r_{i}$, given that $s_{i}$ and $h_{i}$ are both functions of $r_{i}$. By summarizing all the individual deflection parameters through Eq. (2), the total deflection in radial and circumferential direction is proposed in the form of Eqs. (16) and (17).

$$
\begin{aligned}
& U_{r}=f_{r}\left(r_{i}\right) \\
& U_{\theta}=f_{\theta}\left(r_{i}\right)
\end{aligned}
$$

where $U_{r}$ and $U_{\theta}$ are the total deflections in radial and circumferential direction, respectively.

In addition, the involute profile of toothed die and workpiece deflects non-uniformly during forging. Thus, the involute of the die tooth should be modified to forge gears with standard involute. Equation (18) is the involute equation. The equation set modified with Eq. (16) in the radial direction and with Eq. (17) in the circumferential direction is proposed in the form of Eq. (19).

$$
\begin{aligned}
& \left\{\begin{array}{l}
r=\frac{d_{b}}{2} \sqrt{1+\omega^{2}} \\
\theta=\omega-\arctan \omega
\end{array}\right. \\
& \left\{\begin{array}{l}
r=\frac{d_{b}}{2} \sqrt{1+\omega^{2}}+f_{r}\left(r_{i}\right)\left(\frac{d_{b}}{2} \sqrt{1+\omega^{2}}\right) \\
\theta=\omega-\arctan \omega-\frac{f_{\theta}\left(r_{i}\right)}{r} \frac{180}{\pi}
\end{array}\right.
\end{aligned}
$$

where $d_{b}$ is the diameter of base circle and $\omega$ is a parameter related to the pressure angle.

\subsection{Finite element simulation for forging process and involute deflection}

In the theoretical model, four factors are considered for calculation. However, these factors cannot be measured separately through experiment. Forging trials can only be used to verify the final result of the theoretical calculation. FE simulation here was performed to validate the theoretical model predictions for individual deflections. In other words, the theoretical model and FE simulation both predict the tooth deflection, while the FE simulation and experimentation both verify the theoretical model. The theoretical model is more convenient and efficient as a calculation for engineers.

The five parts for the FE model shown in Fig. 5a were constructed with Pro-ENGINEER for geometry and DEFORM-3D for simulation. Because of symmetry around the centerline of each tooth, a length consisting of $7.7 \%$ (two teeth) of the die was modeled. The punch, counter punch, and mandrel were modeled as rigid bodies with a preheat temperature of $100{ }^{\circ} \mathrm{C}$, while the toothed die was modeled as an elastic one with the same preheat temperature. The billet was modeled as a viscoplastic body at $1000{ }^{\circ} \mathrm{C}$, and the material model defined in DEFORM-3D at the temperature is used for

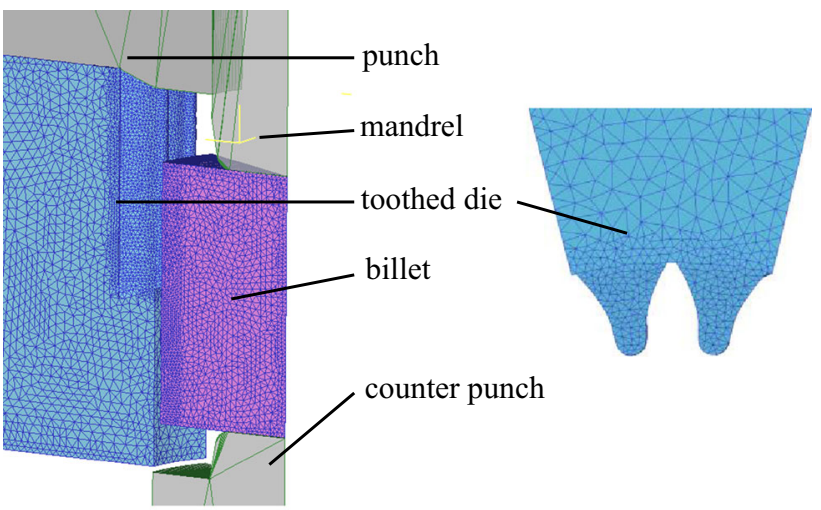

(a) FE model

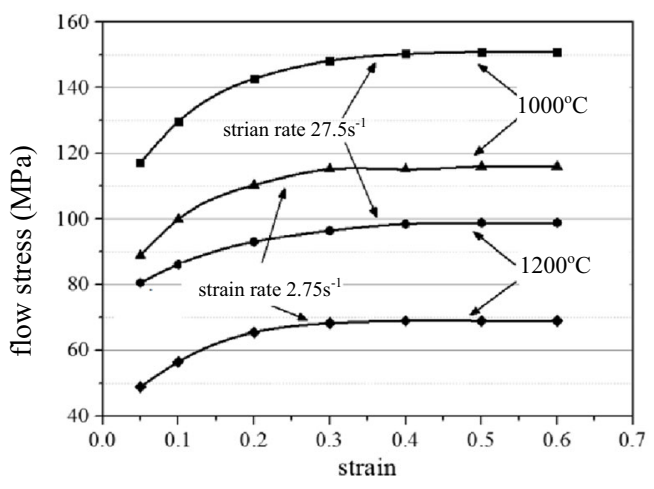

(b) Material properties at different temperature and strain rates

Fig. 5 FEM model for gear forging, a FE model and $\mathbf{b}$ mechanical properties of $20 \mathrm{CrNiMo}$

the FE simulation. The FE simulation was carried out using a computer with a CPU of AMD Phenom II X4 955 and 4GB DDR3 memory, and the computational CPU time for a job is 3-4 h, depending on cases studied. The materials of the toothed die and billet are $\mathrm{H} 13$ and 20CrNiMo, respectively.

Friction prevails at the die-workpiece interface at all times during forging and has a great effect on workpiece deformation and forming load. Therefore, accurately specifying the friction conditions for FE simulation is necessary for obtaining a valid prediction. The constant shear friction law is usually used for simulation of bulk forming involving large plastic deformation. In this study, a frictional factor of $f=0.3$ between the interfaces of billet and dies was used in FE simulation according to the work on friction coefficient in hot precision forging [20-22].

Figure 5a shows the FE model with tetrahedral meshes for the toothed die and billet. The billet was a hollow cylinder. A total of 50,000 elements were generated on the billet and 100, 000 on the toothed die. The meshes on the tooth region of the die and outer layer of the billet were locally refined with the ratio of 0.1 . The tool components are subjected to elastic deformation during forming, which is small. Thus, the tool mesh distortion during the forming is very limited, which is similar to the undeformed state of the tool, as shown in Fig. 5a. Global 
remeshing was adopted, for which the relative interference depth with the ratio of 0.7 was used in this work. Namely, when an element edge of meshed body was penetrated by the dies through a relative amount of 0.7 , new meshes all over the deformed object were generated. For symmetry, the two edges of the billet and toothed die were set as symmetry planes. The material property data is shown in Fig. 5 b.

The conditions for the forging simulation were the same as for the actual process. The process consisted of the following five stages: preheating the die, loading, unloading, ejection, and cooling the workpiece. Calculation of boundary conditions, such as the shape, temperature, and stress states of each object at each stage, was based on the simulation results of the former stage.

Twelve tracking points were chosen on the involute profile of gear and die, to obtain the amount of tooth deflection in forging process, as shown in Fig. 6. Radial and circumferential displacements at each step of forging process were obtained using the software.

\subsection{Computational results}

The values of parameters for the theoretical calculation are illustrated in Table 1.

The theoretical calculation and FE simulation results for each deflection and total deflection along the involute profile are shown in Figs. 7 and 8. The solid lines represent the results of theoretical calculation, and the symbols represent the FE simulation results from the 12 points chosen on the involute profile. The horizontal coordinate $r_{i}$ is the radial distance from each point $P_{i}$ to the gear center, and the vertical coordinate represents the deflection at that point.

Figure 7a illustrates the thermal contraction (in red) and elastic recovery (in black) of the workpiece in a radial direction. The amount of thermal contraction ranges from 0.391 to
Table 1 Parameter values for calculation

\begin{tabular}{llll}
\hline Parameter & Value & Parameter & Value \\
\hline$T_{0}$ & $20{ }^{\circ} \mathrm{C}$ & $T_{f}$ & $1000{ }^{\circ} \mathrm{C}$ \\
$T_{p}$ & $100{ }^{\circ} \mathrm{C}$ & $\beta_{w}$ & $1.2 \times 10^{-5}$ \\
$\beta_{d}$ & $1.2 \times 10^{-5}$ & $\delta$ & $0.17 \mathrm{~mm}$ \\
$R_{1}$ & $38.69 \mathrm{~mm}$ & $\mu$ & 0.3 \\
$R_{2}$ & $90 \mathrm{~mm}$ & $\sigma_{s}$ & $180 \mathrm{MPa}$ \\
$R_{3}$ & $130 \mathrm{~mm}$ & $E^{\prime}$ & $50 \mathrm{GPa}$ \\
$D_{1}$ & $77.38 \mathrm{~mm}$ & $\rho^{\prime}$ & 0.43 \\
$E$ & $198 \mathrm{GPa}$ & $\rho$ & 0.3 \\
\hline
\end{tabular}

$0.451 \mathrm{~mm}$ and elastic recovery from 0.068 to $0.079 \mathrm{~mm}$, increasing gradually from the base circle to the addendum. The results show a good consistency along tooth profile with the maximum deviation of $3.8 \%$ for thermal contraction and $27.1 \%$ for elastic recovery between theoretical calculation and FE simulation results.

Figure $7 \mathrm{~b}$ illustrates the thermal expansion (in red) and elastic expansion (in black) of the toothed die. The amount of thermal expansion ranges from 0.032 to $0.037 \mathrm{~mm}$ and increases gradually from the base circle to the addendum. The maximum deviation between theoretical calculation and FE simulation results appears on the addendum as large as $2.3 \%$. The amount of elastic expansion ranges from 0.016 to $0.013 \mathrm{~mm}$ and decreases gradually from the base circle to the addendum. The deviation on base circle between theoretical calculation and FE simulation results is the largest with the value of $22.5 \%$.

Figure $7 \mathrm{c}$ illustrates the theoretical and FE simulation results of the total amount of the radial deflection $U_{r}$ along the involute profile. The dimensional difference between the die and the forged gear is calculated using Eq. (2). The results show that the dimension difference ranges from 0.275 to $0.322 \mathrm{~mm}$ and increases gradually from the base circle to the
Fig. 6 Tracking points on a tooth of forged gear (left) and die (right)
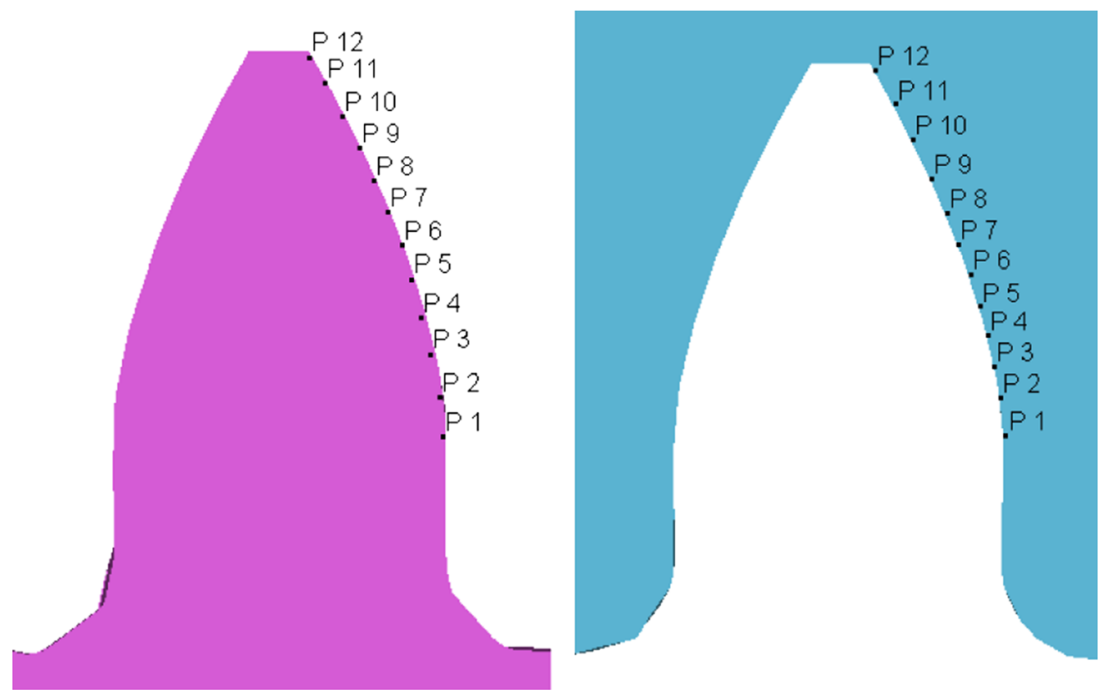


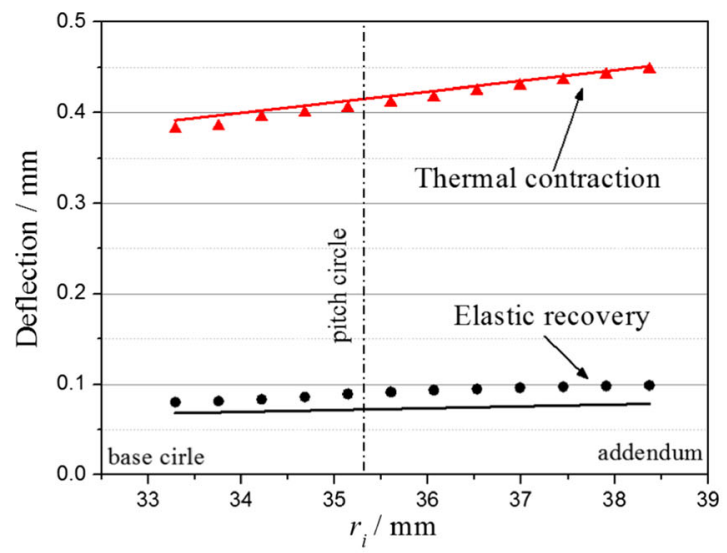

(a) Workpiece tooth deflection

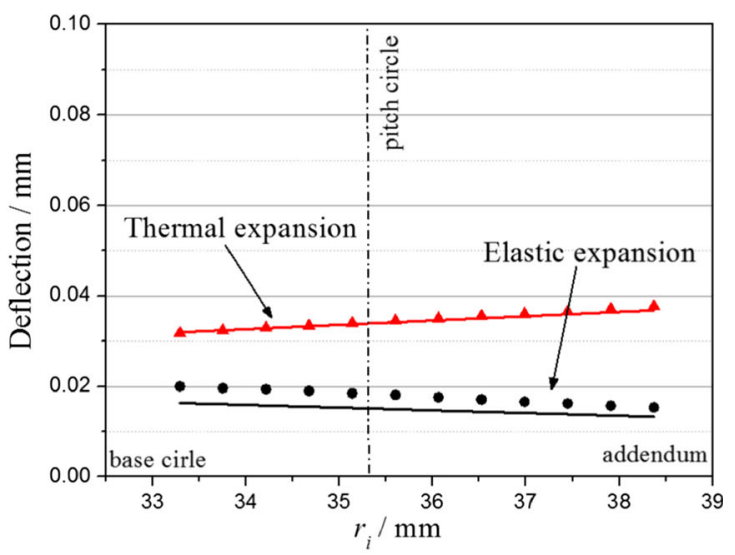

(b) Die tooth deflection

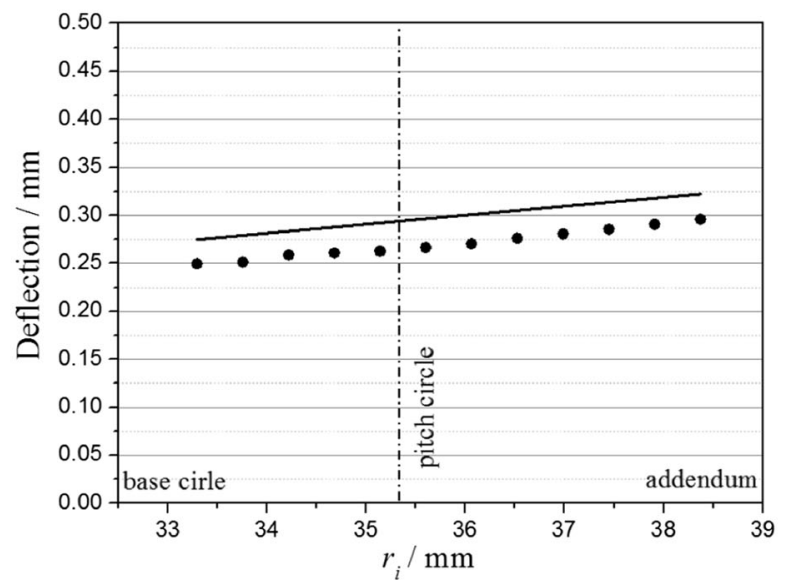

(c) Dimensional difference between the die and the forged gear $U_{r}$

Fig. 7 Comparison of the theoretical (solid curves) and FE (symbols) prediction results of involute deflections in radial direction

addendum. The maximum deviation between theoretical and FE simulation results is less than $11.4 \%$. That the FE simulation is larger than theoretical prediction in elastic recovery (Fig. 7a) of workpiece and elastic expansion of die (Fig. 7b) and smaller than theoretical prediction in thermal contraction (Fig. 7a) of workpiece mainly leads to the difference in Fig. 7c between the theoretical prediction and FE simulation.

The results show that thermal contraction of workpiece is the main factor that influences the amount of the tooth deflection in hot precision forging of a gear, which covers $70 \%$ of total deflection. While the elastic recovery of workpiece covers $21 \%$, the thermal and elastic expansions of die cover 6 and $3 \%$, respectively. The deviation between the theoretical calculation and FE prediction is less than $12 \%$. The curves of each radial deflection on involute profile appear to be straight lines, as they are linearly related to $r_{i}$ according to the model. The elastic die expansion is in inverse ratio to $r_{i}$ since it is in direct ratio to $h_{i}$, which has negative correlation with $r_{i}$.

The circumferential deflections which include elastic workpiece recovery and die expansion are illustrated in Fig. 8a, b. For both theoretical and FE predictions, the amount of elastic workpiece recovery ranges from 5 to $1 \mu \mathrm{m}$ and decreases gradually from the base circle to the addendum non-linearly. The theoretical calculation of the die expansion ranges from 1 to $2 \mu \mathrm{m}$ and increases gradually from the base circle to the addendum. However, the simulation result decreases around the addendum, given that the cylinder zone has limited the circumferential deflection of the tooth zone, thereby leading to this decreased circumferential deflection. The theoretical model did not consider the constraint of cylinder zone on the deflection of tooth zone, thereby causes a difference between the theoretical calculation and FE simulation around the addendum. Since the difference between the theoretical calculation and FE simulation around the addendum is within $2 \mu \mathrm{m}$, which is much smaller compared to the radial deflection, it is negligible.

Figure $8 \mathrm{c}$ illustrates the theoretical and FE simulation results of the total amount of the circumferential deflection $U_{\theta}$ along the involute profile. The results show that the total deflection ranges from 6 to $3 \mu \mathrm{m}$ and decreases gradually from the base circle to the addendum. Circumferential deflections show decreasing tendency and appear non-linear because they 


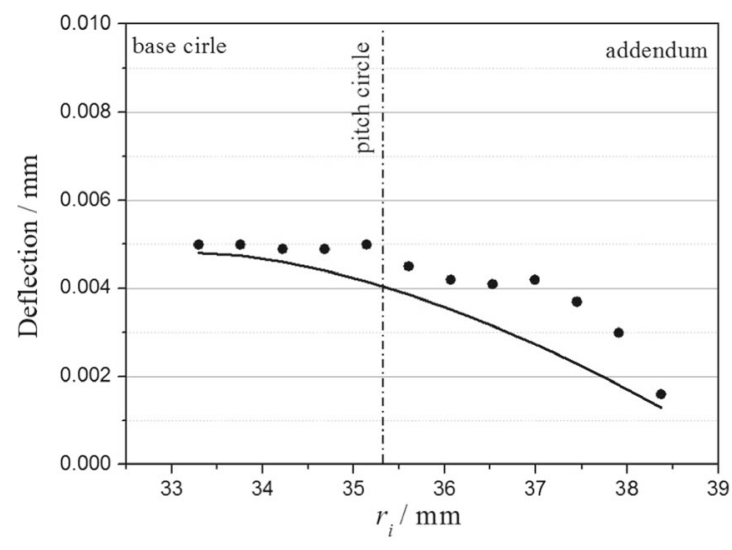

(a) Elastic recovery of workpiece tooth

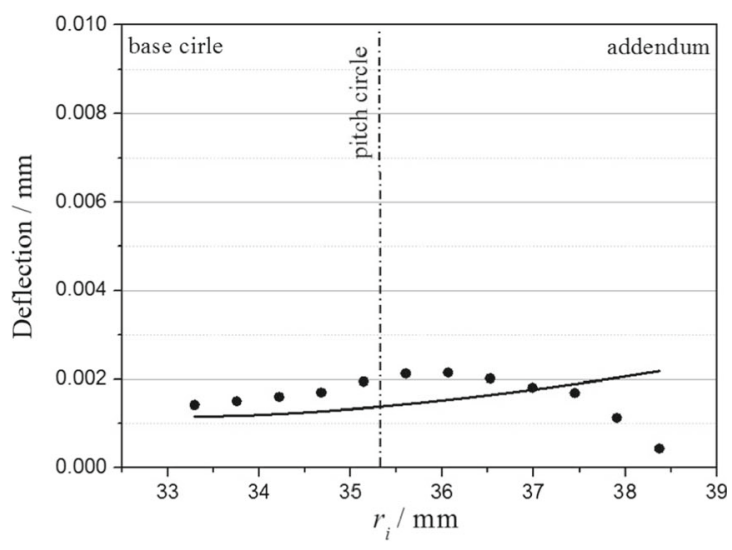

(b) Elastic expansion of die tooth.

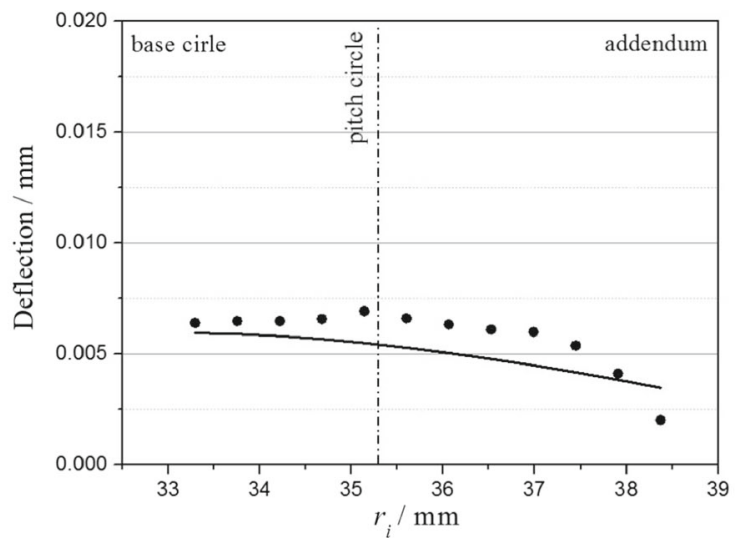

(c) Dimensional difference between the die and forged gear $U_{\theta}$

Fig. 8 Comparison of the theoretical (solid curves) and FE (symbols) prediction results of involute deflections in circumferential direction

are related to gear thickness $s_{i}$, which is non-linear with respect to racial distance to the gear center $r_{i}$. The total circumferential deflection is extremely small and can be ignored in die tooth design because the finishing allowance is 0.05 to $0.1 \mathrm{~mm}$.

\section{Deflection characteristic through tooth width}

\subsection{Theoretical analysis}

In the chosen forging process, the toothed die moves in the tools, and the die cavity is completely closed throughout the process. Thus, the width of the toothed die was designed larger than that of the workpiece to enable the toothed die to move with the bottom die in it. The workpiece contacted the die over the length $b$, and the toothed die experienced non-uniform pressure over its full width, as illustrated in Fig. 9. For the die insert, the inner pressure, exerted by workpiece, was uniformly distributed on the range of the gear width $b$, assuming that the billet material had fully filled the die tooth. However, the outer surface was under the fitting pressure throughout the die width $B$. Thus, the stress non-uniformity throughout the die width caused deflection non-uniformity of the toothed die, thereby leading to the variation on gear workpiece, even if the effect on deflection might be limited during the forging.

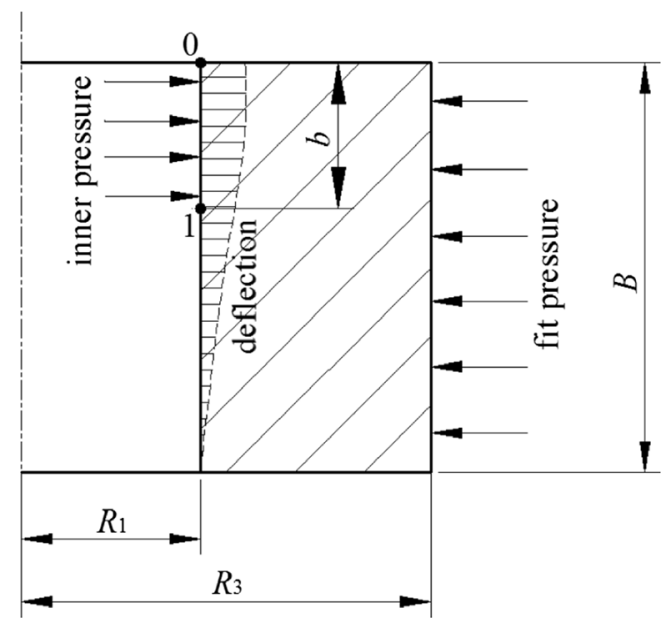

Fig. 9 Force analysis of the toothed die (die insert) in the axial direction 
All effects on the elastic die expansion are analyzed separately to determine the effects on the deflection nonuniformity of the toothed die. According to Eqs. (8) and (9), the effects on the elastic die expansion contain the dimensions of the die, namely, $R_{1}, R_{2}$, and $R_{3}$, and inner pressure, $\sigma_{s}$. $R_{1}$ is a parameter relative to the root circle of the gear and is not a variable. The ratio of $b$ to $B$ is an important factor that affects the deflection non-uniformity of the toothed die. Thus, the model of the deflection non-uniformity can be expressed as a function in variables $R_{2}$ (outer radius of die container), $R_{3}$ (outer radius of die insert), $\sigma_{s}$, and the ratio of $b$ to $B$, as shown in Eqs. (20) and (21).

$\eta_{b}=g\left(R_{2}, R_{3}, \sigma_{s}, \lambda\right)$

$\lambda=b / B$

where $\eta_{b}$ is deflection non-uniformity and $\lambda$ is the ratio of $b$ to $B$.

According to Eqs. (7)-(9), the effects of the dimension $R_{2}$ and $R_{3}$ on the elastic deflection of a toothed die can be calculated separately, as shown in Fig. 10. $R_{2}$ ranges from 90 to $170 \mathrm{~mm}$, and $R_{3}$ ranges from 80 to $120 \mathrm{~mm}$.

The effects of $R_{2}$ and $R_{3}$ are analyzed with the theory formula and that of the other parameters with FEM. This is because the effects of $R_{2}$ and $R_{3}$ can be solved by Eqs. (8) and (9), which are based on the Lame formula simply and accurately. In addition, their effects on die deflection are as small as $4 \mu \mathrm{m}$. Thus, their effects on die deflection non-uniformity can be ignored.

\subsection{FE simulation for deformation non-uniformity}

The inner pressure, $\sigma_{s}$, and ratio, $\lambda$, relate the deflection nonuniformity directly, and their effects are complicated and cannot be adequately expressed by a simple formula. Thus, a simplified FE model for the calculation of the effects of inner

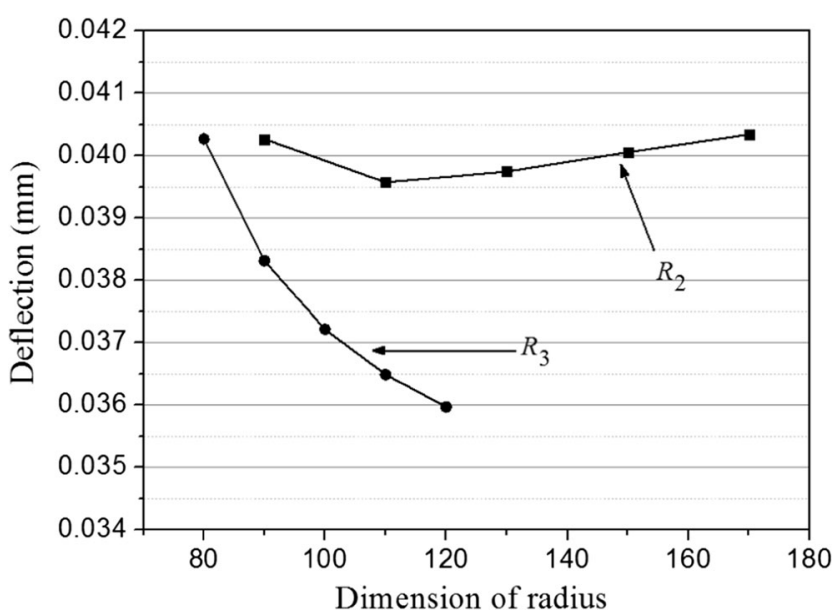

Fig. 10 Effects of $R_{2}$ (when $R_{3}$ is fixed) and $R_{3}$ (when $R_{2}$ is fixed) on elastic die deflection

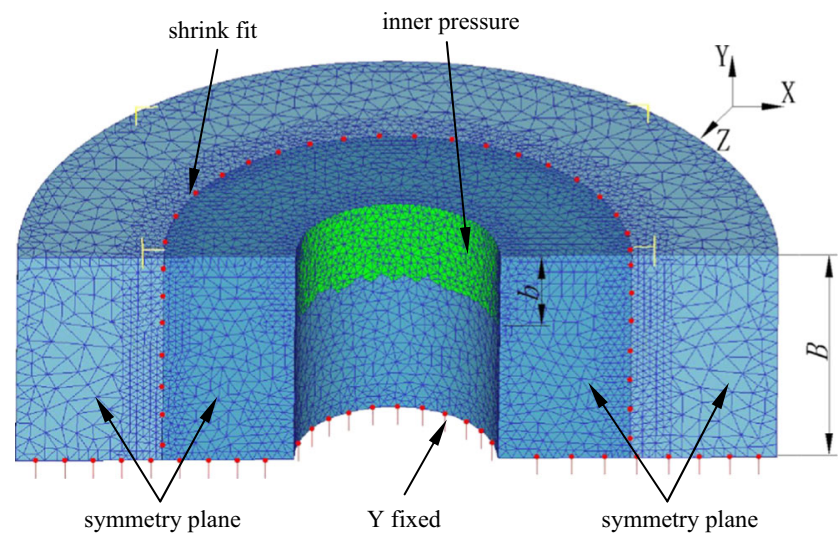

Fig. 11 FE model of the deflection through the tooth width of the simplified toothed die

pressure and ratio $\lambda$ on the deflection non-uniformity of toothed die was built. As shown in Fig. 11, a simplified model of the duplex dies, with no tooth, was inputted to DEFORM$3 \mathrm{D}$ for the FE simulation.

The materials of the die insert and container were $\mathrm{H} 13$ and $40 \mathrm{Cr}$, and both were set as elastic bodies. A total of 50,000 elements were generated on both bodies. The elements on the inner pressure region and shrink fit interface were locally refined with the ratio of 0.2 .

A boundary condition of shrink fit was set between the interfaces of the die insert and container with the interference of $0.15 \mathrm{~mm}$ in the radial direction. The friction coefficient between the die insert and container was 0.1 in cold contact condition. The bottom surface was fixed in the $Y$ direction to restrict the rigid displacement. A half model was used for simulation. Thus, symmetry planes were set as shown in the figure. According to FE simulation results, ranges of inner pressures of 120,180 , and $240 \mathrm{MPa}$ were chosen on the top region of die bore with width of $b$ to study the sensitivity of the inner pressure on deflection. The values of $b$ were 16,24, and $36 \mathrm{~mm}$, while the value of $B$ was $80 \mathrm{~mm}$.

Figure 12 illustrates the simulation results of the effects of inner pressure and ratio $\lambda$ on deflection non-uniformity of the simplified toothed die. Position 0 represents the upper face, and position 1 represents the bottom face of the tooth of the forged gear, as shown in Fig. 9. Figure 12a illustrates that higher internal pressure increases die expansion and deflection non-uniformity when the ratio $\lambda$ is 0.5 . The expansion at position 0 is the largest, given that the top region is under pressure, whereas the bottom region is not, which should be explained as surface 0 is not constraint and 1 is fully constraint by extra width $(B-b)$ of the die. Figure $12 b$ illustrates the effect of ratio $\lambda$ on deflection non-uniformity, when the inner pressure is $180 \mathrm{MPa}$. It shows that large value of $\lambda$ causes larger expansion and non-uniformity of deflection. A larger $\lambda$ means larger width of the tooth and the pressed area, which leads to larger force exerted on the toothed die. However, when $\lambda$ is 
Fig. 12 Effects of a inner pressure and $\mathbf{b}$ ratio $\lambda$ on deflection non-uniformity of the toothed die

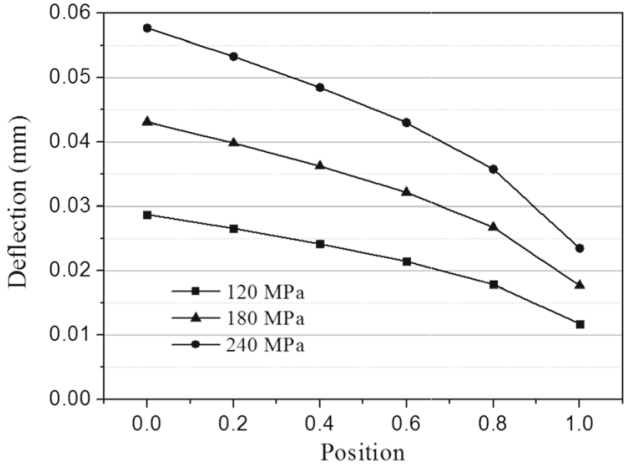

(a) Inner pressure effect $(\lambda=0.5)$

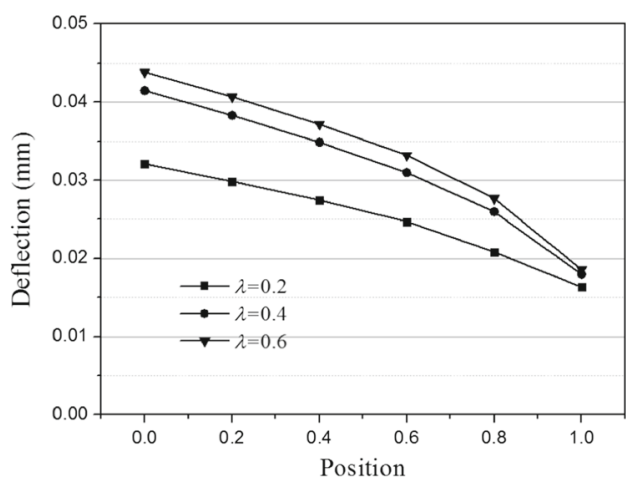

(b) Ratio $\lambda$ effect (inner pressure is $180 \mathrm{MPa}$ ) larger than 0.5 , the increasing trend of deflection nonuniformity on toothed die decreases because the force uniformity is improved. Thus, $\lambda$ of 0.4 and 0.6 have similar effect on deflection non-uniformity.

If the tooth lead of the toothed die is modified according to the calculation result, the top region of die cavity must be smaller than the bottom region. However, the toothed die can hardly be manufactured. Therefore, toothed die with no lead modification was used for the forging trials, and the lead error of the gear tooth can be used to verify analysis validity.

\section{Experimental validation}

The gear forging tests were performed on a $10 \mathrm{MN}$ screw press. The billet, made of $20 \mathrm{CrNiMo}$, was machined as a solid cylinder body. Water-based graphite was used as the lubricant for the billets and dies with the initial average thickness of $0.3 \mathrm{~mm}$. The gear was forged, as the billet was heated to $1000^{\circ} \mathrm{C}$ and the tools were preheated to $100^{\circ} \mathrm{C}$. To minimize billet oxidation, the heating time of billets was kept as short as $10 \mathrm{~min}$ in nitrogen atmosphere. After ejection, the tools were cooled to approximately $100{ }^{\circ} \mathrm{C}$ with a sprayer.

The forged gear and its tooth shape are shown in Fig. 13. The end face was wired-cut to enable the observation of the teeth.

Forming load was recorded using a load cell, which was installed on the punch. Figure 14 shows a comparison of the

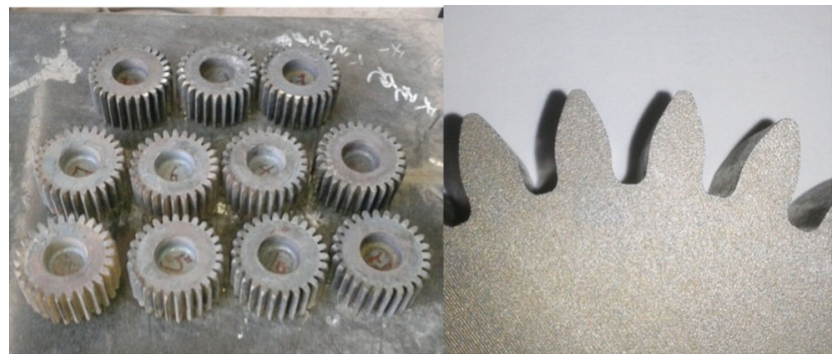

(a) Forged gears

(b) Forged gear teeth

Fig. 13 Photos of forged gears, a appearance of gears and $\mathbf{b}$ gear teeth forming loads between experimental measurements and FE prediction. The measured maximum load was $4085 \mathrm{kN}$, which is $6.5 \%$ less than FE prediction. Between 16- and 30-mm stroke, the computed forging load increases suddenly and then keeps steady state (no increment). This strange behavior from simulation might be due to computational errors in re-meshing and/or contact conditions, which need further investigation. However, in overall, a fairly close agreement between experimental and computational forming loads has been obtained, which validated the FE model.

A modified involute based on the above calculation results was used to design the die tooth. Thus, in theory, the involute profile of the forged tooth should be the standard involute. Table 2 illustrates the measurement result of the involute and lead error of the forged gear at room temperature. The maximum involute error of left face of the tooth is $20.3 \mu \mathrm{m}$, whereas that of right face is $31.9 \mu \mathrm{m}$. The tooth error appears small and stable along the involute profile, thereby ensuring the validity of the model and calculation.

The lead inspection was performed in the direction from the upper to the lower end through the tooth width. Thus, the top of the curve illustrates the lead error of the top region of the forged tooth. The maximum lead error of left face of the

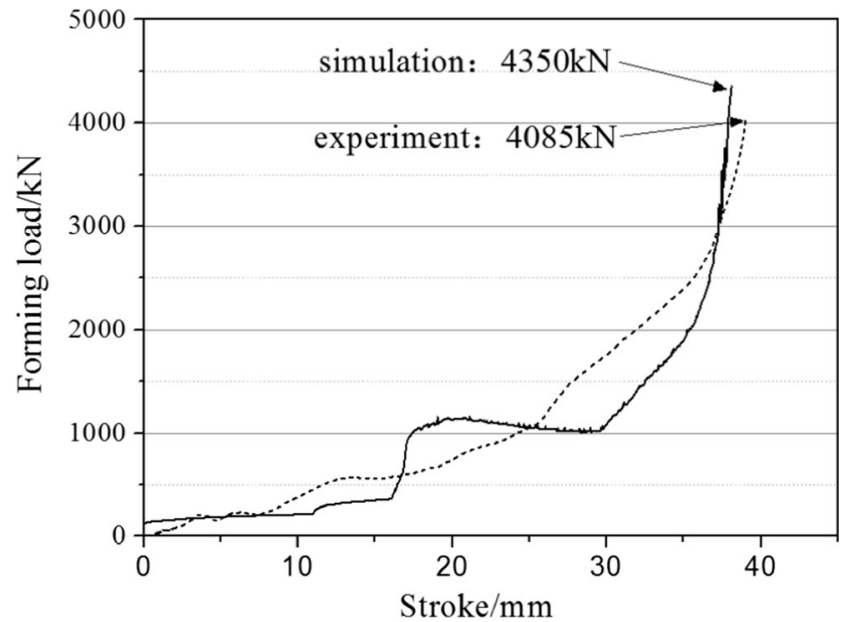

Fig. 14 Comparison of experimental and computational forming loads 
tooth is $53.4 \mu \mathrm{m}$, whereas that of right face is $43.3 \mu \mathrm{m}$. The top of the curves, which tilt toward both sides, reveals the tendency of the deflection non-uniformity through the tooth width of forged gear, which is same with that of simulation result. The top region of the tooth is larger than the bottom region. However, the value is larger than that of simulation result, that is, $25 \mu \mathrm{m}$.

Although the theoretical model is used to modify the die tooth, many other factors cause tooth errors, such as oxidation layer, manufacturing error of toothed die, and measuring datum error (coaxiality of inner bore and tooth). The oxidation layer causes curve jitter and low surface finish. This phenomenon was observed using an optical microscope and measured with software Image-Pro Plus 6.0, as shown in Fig. 15. The thickness of oxidation layer on the surface of forged gear was

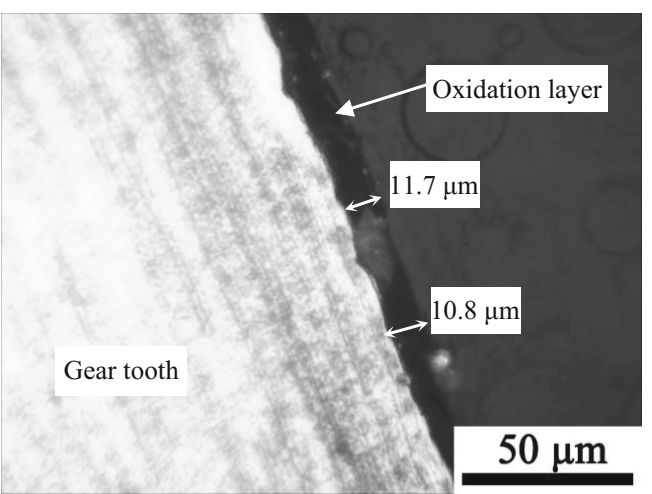

Fig. 15 Oxidation layer on the surface of precision forged gear

10.5 to $15.3 \mu \mathrm{m}$. The manufacturing error of the toothed die and measuring datum error cause the inclination deviation.

Table 2 Results of profile and lead inspection of forged gears

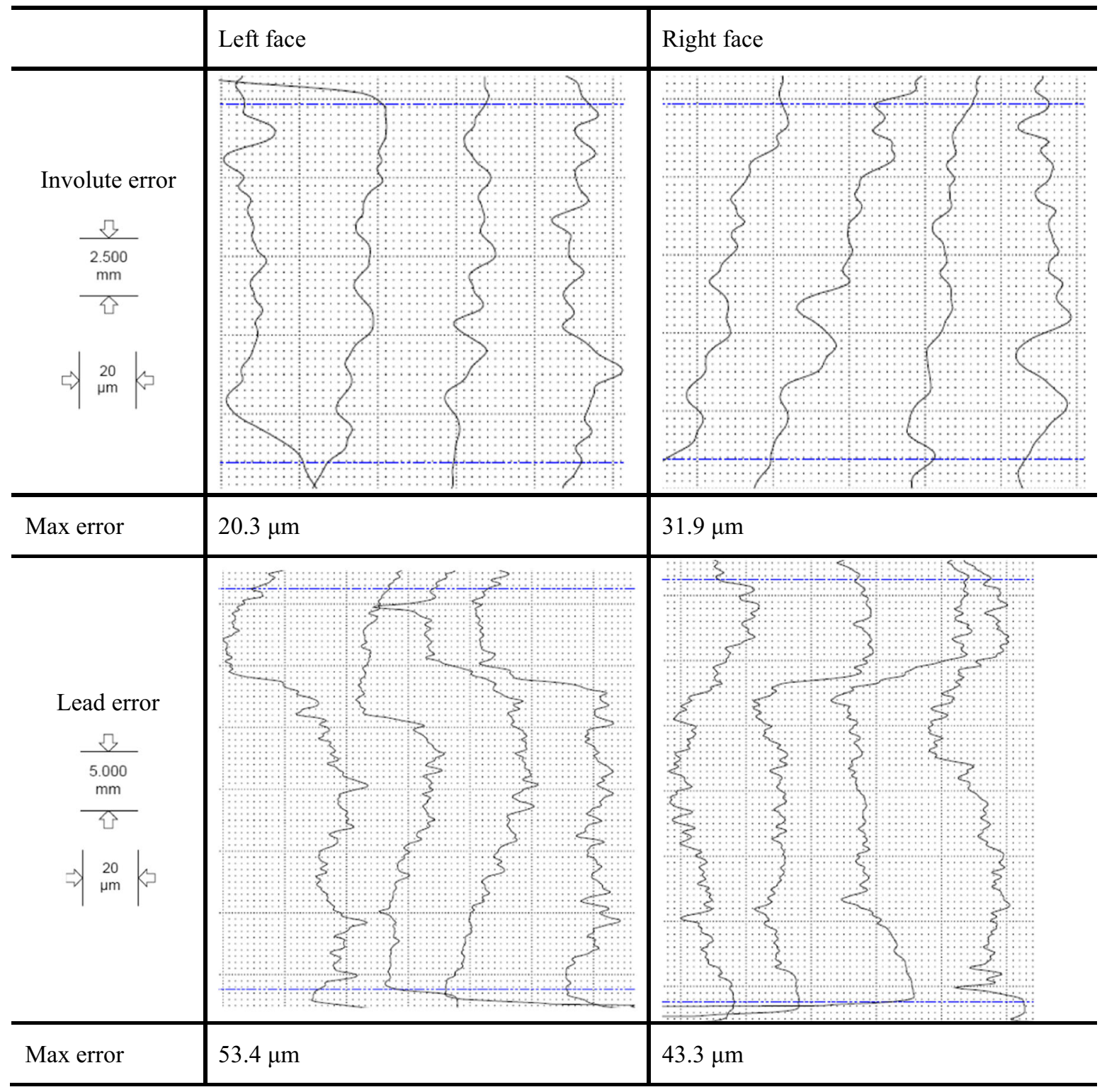




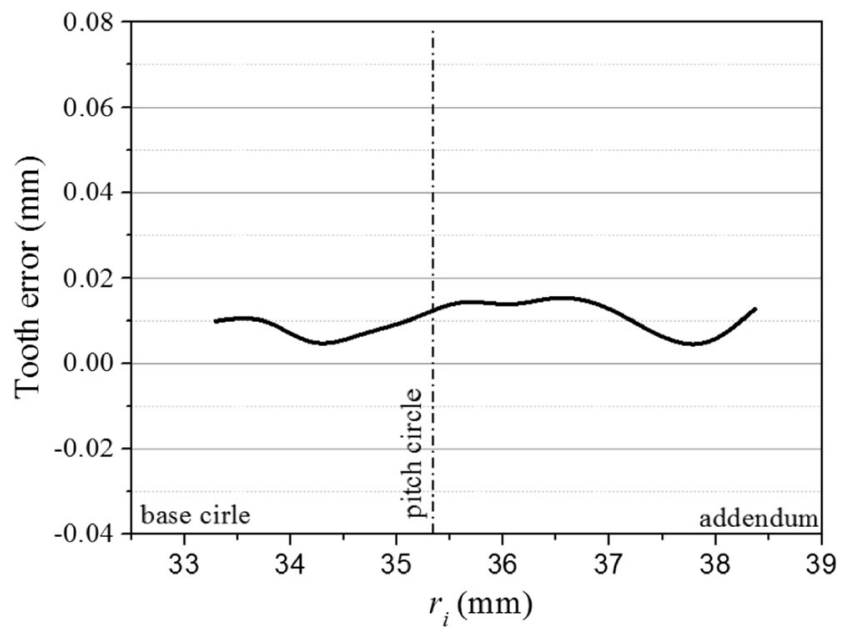

Fig. 16 Measurement result of tooth error of the die

Figure 16 illustrates the measurement result of tooth error of the die. The tooth error of the die was measured using the measurement machine, VMS-3020H, and resulted in maximum error of approximately $13 \mu \mathrm{m}$, which cause a significant error. The involute error of right face, which is mainly derived from the involute tilted error, appears larger than that of left face, whereas the involute tilted error of left face is low. Thus, the involute tilted error may result from the manufacturing error of measuring datum (bore and end face) of the forged gear.

There are two reasons that cause the difference in lead error. The manufacturing error of the die tooth could be as large as approximately 15 to $20 \mu \mathrm{m}$, given that the toothed die was made with EDM, in which the electrode loss increased with the process performed. Thus, the bottom region of the die tooth was smaller in dimension than the top region. The other reason is the non-uniformity of material filling through the tooth width, given that the tooth width is large. The alternative die structure improved the material filling in the bottom region prior to the top region, so that the bottom region was exerted large pressure through the billet when filling the top region. Thus, the size of the bottom corner of the forged teeth was larger than that in the calculation result, which leads to the close size in the bottom corner and middle of the tooth, as the measured curves illustrated. The inspection results verify the validity of the theoretical and FE model for tooth deflection.

\section{Conclusions}

1) In the process of hot precision forging, the following four major factors influence the amount of tooth error: thermal expansion of the die during preheating, elastic expansion of the die during forging, elastic recovery of the workpiece during ejection, and thermal contraction of the workpiece during cooling. The amount of thermal contraction and elastic recovery of workpiece is predominant, which covers approximately $90 \%$ of total deflection.

2) The distribution of radial deflection on involute profile is linear, given that each deflection is related to $r_{i}$ linearly. However, the circumferential deflection shows decreasing tendency and appears non-linear because it is related to gear thickness $s_{i}$, which is non-linear to racial distance to the gear center $r_{i}$.

3) Deflection non-uniformity of toothed die through the tooth width is mainly determined by inner pressure and the ratio of tooth width to die width. The die expansion at the top region of tooth is large, whereas that at the bottom region is small. The large value of the ratio of tooth width to die width and the inner pressure both cause large expansion and deflection non-uniformity.

Acknowledgments The authors would like to gratefully acknowledge the support of the National Natural Science Foundation of China (No. 51375042); also, this project got the funding support from Beijing Laboratory of Modern Transport Metal Materials and Processing Technology.

Open Access This article is distributed under the terms of the Creative Commons Attribution 4.0 International License (http:// creativecommons.org/licenses/by/4.0/), which permits unrestricted use, distribution, and reproduction in any medium, provided you give appropriate credit to the original author(s) and the source, provide a link to the Creative Commons license, and indicate if changes were made.

\section{References}

1. Behrens BA, Doege E, Reinsch S, Telkamp K, Daehndel H, Specker A (2007) Precision forging processes for high-duty automotive components. J Mater Proc Tech 185:139-146

2. Jeong MS, Lee SK, Yun JH, Sung JH, Kim DH, Lee S, Choi TH (2013) Green manufacturing process for helical pinion gear using cold extrusion process. Int J Precis Eng Man 14:1007-1011

3. Abdel-Rahman ARO, Dean TA (1981) The quality of hot forged spur gear forms. Part I: mechanical and metallurgical properties. Int J Mach Tool Des Res 21:109-127

4. Yang TS (2008) Prediction of maximum forming load and billet dimensions using an abductive network and finite element method simulation of a near net-shaped helical gear forging. Proc I Mech Eng B-J Eng 223:289-304

5. Feng W, Hua L, Han XH (2012) Finite element analysis and simulation for cold precision forging of a helical gear. J Cent South Univ T 19:3369-3377

6. Behrens BA, Odening D (2009) Process and tool design for precision forging of geared components. Int J Mater Form 21:125-128

7. Hu CL, Wang KS, Liu QK (2007) Study on a new technological scheme for cold forging of spur gears. J Mater Proc Tech 187:600 603

8. Cai J, Dean TA, Hu ZM (2004) Alternative die designs in net-shape forging of gears. J Mater Proc Tech 150:48-55

9. Ohga K, Kondo K, Jitsunari T (1982) Research on precision die forging utilizing divided flow: second report, experimental study of processes utilizing flow relief-axis and relief-hole. Bull JSME 25: $1836-1842$ 
10. Wang GC, Zhao GQ, Xia SS, Luan YG (2003) Numerical and experimental study on new cold precision forging technique of spur gears. T Nonferr Metal Soc 13:798-802

11. Alves ML, Rodrigues JMC, Martins PAF (2001) Cold forging of gears: experimental and theoretical investigation. Fin Elem Anal Des 37:549-558

12. Dean TA (2000) The net-shape forming of gears. Mater Des 21: 271-278

13. Liu H, Xi QP, Huo YJ, Sun HX, Zhang XC, Li YH, Liu BX, Chen JD (2004) Numerical simulation to mold modification of cold precision forging of spur gear. J Xi'an Jiao Univ 38:1186-1190

14. Kang JH, Lee KO, Je JS, Kang SS (2007) Spur gear forging tool manufacturing method considering elastic deformation due to shrink fitting. J Mater Proc Tech 187:14-18

15. Choi JC, Choi Y (1999) Precision forging of spur gears with inside relief. Int J Mach Tool Manu 39:1575-1588

16. Stone E, Cai J, Hu ZM, Dean TA (2003) An exercise in cold ironing as the post-forging operation for net-shape manufacture. J Mater Proc Tech 135:278-283
17. Chang YC, Hu ZM, Kang BS, Dean TA (2002) A study of cold ironing as a post-process for net-shape manufacture. Int J Mach Tool Manu 42:945-952

18. Sadeghi MH, Dean TA (1991) Analysis of dimensional accuracy of precision forged axisymmetric components. P I Mech Eng B-J Eng 205:171-178

19. Abdel-Rahman ARO, Dean TA (1981) The quality of hot forged spur gear forms. Part II: tooth form accuracy. Int J Mach Tool Manu 21:129-141

20. Shan DB, Xu J, Wang CJ, Guo B (2009) Hybrid forging processes of micro-double gear using micro-forming technology. Int J Adv Manuf Technol 44:238-243

21. Sadeghi MH (2003) Gear forging: mathematical modeling and experimental validation. J Manuf Sci E-T ASME 125:753-762

22. Yilmaz NF, Eyercioglu O (2009) An integrated computer-aided decision support system for die stresses and dimensional accuracy of precision forging dies. Int J Adv Manuf Technol 40:875-886 